\title{
Does Urbanization Affect Predation of Bird Nests? A Meta-Analysis
}

\author{
Ernö Vincze ${ }^{1,2,3 *}$, Gábor Seress ${ }^{2}$, Malgorzata Lagisz $^{4}$, Shinichi Nakagawa ${ }^{4}$, \\ Niels J. Dingemanse ${ }^{1}$ and Philipp Sprau ${ }^{1}$ \\ ${ }^{1}$ Behavioral Ecology, Department of Biology, Ludwig Maximilians University München, Planegg-Martinsried, Germany, \\ ${ }^{2}$ Department of Limnology, University of Pannonia, Veszprém, Hungary, ${ }^{3}$ MTA-PE Evolutionary Ecology Research Group, \\ Veszprém, Hungary, ${ }^{4}$ Evolution and Ecology Research Centre, School of Biological, Earth and Environmental Sciences, \\ University of New South Wales, Sydney, NSW, Australia
}

OPEN ACCESS

Edited by:

Caroline Isaksson

Lund University, Sweden

Reviewed by:

Frederick R. Adler,

University of Utah, USA

Loren B. Byrne,

Roger Williams University, USA

*Correspondence:

Ernő Vincze

erno.vincze@gmail.com

Specialty section:

This article was submitted to Urban Ecology,

a section of the journa

Frontiers in Ecology and Evolution

Received: 02 February 2017 Accepted: 24 March 2017 Published: 11 April 2017

Citation:

Vincze E, Seress G, Lagisz M, Nakagawa S, Dingemanse NJ and Sprau P (2017) Does Urbanization Affect Predation of Bird Nests? A

Meta-Analysis. Front. Ecol. Evol. 5:29.

doi: 10.3389/fevo.2017.00029
Urbanization can affect interspecific interactions such as predator-prey relationships. Several hypotheses have been postulated to predict how predation on bird nests changes along urbanization gradients; some predict increased and others decreased predation pressures in urban compared to rural habitats. Using a formal meta-analytical approach, we carried out a systematic literature review to test whether predation on natural and artificial bird nests increased or decreased with urbanization. We found that the effect was highly heterogeneous among studies, due to contrasting results between studies that used artificial nests and those that used natural nests. For artificial nests, survival rate tended to decrease with increasing urbanization, with higher predation in more urbanized study sites. For natural nests, survival tended to increase with the level of urbanization. The latter finding supports predictions of the "urban habitats as predation-safe zones" and "urban nest predator paradox" hypotheses, but the effect may be confounded by many studies not distinguishing between predation and other sources of mortality. None of the other considered methodological and ecological variables explained the variation in a robust way. The discrepancy between the results of artificial and natural nest studies may be due to differences in experimental design (e.g., cavity nests have been more commonly studied in natural nest studies), intrinsic differences between the two nest types (e.g., lack of parental nest defense in artificial nests), or sampling bias. We conclude that the direction of the relationship between urbanization and nest predation is likely to depend on the methodology of the study. Therefore, results from studies using different methodologies, particularly natural or artificial nests, should be generalized with caution to avoid over-interpretations.

Keywords: urban ecology, interspecific interactions, avian nest mortality, predation pressure, survival rate, top-down control, meta-regression

\section{INTRODUCTION}

Urbanization, i.e., the expansion and development of cities, suburban and exurban areas, creates novel, and often challenging, environments for wild animals. Compared to natural areas, urban habitats are characterized by many altered environmental factors such as elevated levels of chemical, noise and light pollution, transformed landscapes or various disturbances resulting from the increased human population (Marzluff et al., 2001b; Sol et al., 2013; Sprau et al., 2016). These altered environmental factors impact ecological factors that affect population dynamics and persistence, such as food availability and predation pressure (Seress and Liker, 2015). As a consequence, interspecific interactions such as predator-prey relationships can differ qualitatively between 
urban and non-urban habitats (Faeth et al., 2005; Chace and Walsh, 2006; Fischer et al., 2012).

Although avian species are frequently used model organisms in urban ecological studies on predation, it is unclear how urbanization affects predation on birds and their nests. Different mechanisms have been postulated that predict either increased or decreased rates of predation in cities (Chamberlain et al., 2009)While some hypotheses, as detailed below, suggest that prey species thrive in cities because those habitats are "predator-safe zones” (Gering and Blair, 1999; Ryder et al., 2010; Møller, 2012), others predict an opposite relationship, with predators thriving in cities and imposing increased predation pressure on their prey (Jokimäki and Huhta, 2000; Haskell et al., 2001). Notably, the suggested mechanisms are non-exclusive, and thus any difference in predation rates between urban and rural habitats, or lack of it, may also be a net result of their joint effects. It is also possible that the net effect is zero, and empirical evidence in either direction is just the upper and lower extremes of a distribution around it.

For example, larger species are often less tolerant toward high human density; predators, usually larger than their prey, are therefore expected to be present in lower abundances in cities compared to natural habitats, resulting in lower predation rates (Møller, 2012). However, many opportunistic, mediumsized predator species, such as crows (Corvus sp.) (Marzluff and Neatherlin, 2006; Kövér et al., 2015), magpies (Pica pica) (Jerzak, 1997), or raccoons (Procyon lotor) (Haskell et al., 2001; Prange and Gehrt, 2004), are known to reach higher densities in urban compared to rural habitats. Such patterns suggest that these species also pose higher predation pressures on their prey species in urban habitats. Similarly, domesticated predators, particularly cats (Felis silvestris catus), are often found in extremely high abundances in urban and suburban areas (Sims et al., 2008), and increase the risk of predation for avian species (Baker et al., 2008; Balogh et al., 2011; Stracey, 2011). Other authors, by contrast, suggest that, despite this high abundance of certain predator species, urban predation rates can still be low if urban prey populations are also relatively large, which may explain the "urban predation paradox" (Rodewald et al., 2011; Fischer et al., 2012).

Environmental characteristics of urban habitats, such as noise (Slabbekoorn and Halfwerk, 2009), light (Navara and Nelson, 2007), and vegetation (Chace and Walsh, 2006) can also affect predation rates, again either positively or negatively. For example, high noise levels in cities may increase the difficulty for prey animals to detect predation risk and to respond to it, resulting in increased predation rates (Templeton et al., 2016). However, urban noise can also have an opposite effect, as it may disturb predators and make it more difficult for them to detect their prey, thus resulting in decreased predation rates (Francis et al., 2009), For example, noise is known to influence begging calls of nestlings (Leonard and Horn, 2008), and it might be possible that it conceals the vocalizing chicks from predators. Similarly, artificial lighting can make prey more conspicuous to predators, increasing predation rates (Clarke, 1983), but also make it easier for prey to detect predators (Gorenzel and Salmon, 1995). Furthermore, vegetation is more fragmented in urban habitats, and fragmentation can increase predation risk (Hartley and
Hunter, 1998), possibly because there is less shelter for prey animals.

Weaker anti-predator responses (e.g., shorter flight initiation distances, lower vigilance behavior, shorter recovery rates) of urban animals (compared to non-urban conspecifics) have also been described as indirect evidence for decreased predation risk in cities (Møller and Ibáñez-Álamo, 2012). However, apart from a handful of experiments with predator dummies (Seress et al., 2011) or playbacks of alarm calls (Myers and Hyman, 2016), the majority of empirical studies comparing anti-predator behavior of urban and rural populations have been conducted using humans as potential predators (reviewed by Samia et al., 2015). While humans might be perceived as potential predators, they usually do not represent a direct predation threat (Beale and Monaghan, 2004). Therefore, these results are difficult to generalize to non-human predators. In fact, tolerance of humans can also lead to decreased vigilance in prey, which can lead to higher predation rates in urban areas (Geffroy et al., 2015).

Studies investigating mechanisms postulated above have used a diverse array of methods. Some studies compare the diet composition of urban and rural predators, e.g., using remains found in pellets of birds of prey (e.g., Brack et al., 1985; Kristan et al., 2004; Lesiński et al., 2009). However, while pellet analysis can be informative regarding the relative predation pressure on various prey species, it tells very little about the overall predation pressure. Another approach is the direct monitoring of prey mortality. Studies on post-fledging and adult mortality are uncommon, because population censuses and capture-recapture methods (Chiron and Julliard, 2007; Brown and Graham, 2015) might estimate survival inaccurately, or because tracing individual prey animals (e.g., by radio-telemetry; McCleery et al., 2008; Ausprey and Rodewald, 2011; Balogh et al., 2011; Shipley et al., 2013) is often costly and based on small sample sizes. Bird nests, in contrast, are immobile, easy to monitor, and are often preyed upon by various predator species. Thus, natural bird nests, as well as artificial nests baited with real or fake eggs, are most often used as study system when comparing predation rates between differently urbanized habitats. However, some factors may increase heterogeneity in effects reported in the literature, hindering interpretation and generalization of results, such as differences in characteristics between artificial and natural nests (Moore and Robinson, 2004; Robinson et al., 2005), nesting characteristics specific to the study species (e.g., nest height from the ground, nest openness), and inconsistent, study-specific definitions of urbanization (Marzluff et al., 2001a).

In this paper, we investigate how predation rates on bird nests change with habitat urbanization by conducting a formal metaanalysis. To our knowledge, this paper is the first formal metaanalysis that attempts to quantitatively synthetize published results concerning this question. We hypothesize that if the mechanisms that increase predation rate with urbanization, as detailed above, outweigh those that decrease predation rate, we will find higher predation rates in urban habitats, and vice versa. Furthermore, we also conducted meta-regressions (meta-analyses with additional explanatory variables, henceforth referred to as "moderators"), to explore whether variation in effect size between studies can be explained by differences in 
study design (using natural vs. artificial nests), bird species, or definitions of predation rate or urbanization.

\section{METHODS}

\section{Literature Screening and Data Collection}

We followed the PRISMA protocol for collecting data from the published literature (Moher et al., 2009; Nakagawa and Poulin, 2012). We first performed literature searches using the online search engines Scopus (http://www.scopus.com/) and Web of Science (http://wokinfo.com/) with the following keyword string: "nest* AND (*urban* OR anthropogenic OR rural) AND predat*." We then screened the titles and abstracts of the papers found by the search, and decided whether the following criteria were met:

- The abstract indicated that study was conducted on bird nests, either by monitoring natural bird populations, or by performing experimental studies on artificial nests baited with real or fake eggs.

- The abstract indicated that the survival (or mortality) rates of these nests were reported in the main text as a function of an urbanization gradient.

One of us (EV) screened all the abstracts found by Scopus, while another (GS) screened all the abstracts found by searching the Web of Science (WoS), and coded whether the papers met the selection criteria or not. Papers that were found by both search engines were scored by both observers and used for testing between-observer repeatability (see Table S1). We also performed backward searches, i.e., screened reference lists of relevant papers and reviews, and visited author websites, to find additional eligible papers that might have been missed during the systematic database searches. We did not limit our search to English-language papers, but also included papers written in Spanish, French, German, Russian, or Polish.

Papers considered to meet the selection criteria by at least one observer were taken forward for full-text screening. Each paper was screened by a single person. During full-text screening we excluded the papers that:

- Did not define an urbanization gradient (i.e., because all studied sites had the same level of urbanization, or because the information was not provided);

- Addressed other forms of anthropogenic disturbance (i.e., fragmentation of natural or semi-natural habitats, agricultural practices) without using any urban study sites;

- Did not report any nest survival (or mortality) data, only presence/absence of species, adult survival or individual offspring survival;

- Had overlapping data with another paper (i.e., when the two papers tested different hypotheses using the same dataset). In these cases we included the paper which contained the most information (i.e., reported more complete data or used a larger data set);

- Did not report their nest survival data in relation to urbanization, despite conducting the study in differently urbanized habitats;
- Reported the data in a format that did not allow extraction of effect sizes (e.g., multivariate regressions, mixed-effects models, daily survival rates from logistic exposure modelssee further justification in Section Data Extraction).

In the latter two cases, we contacted the original authors provided that their e-mail addresses were available. We got feedback from 19 out of 28 contacted authors. For four studies, we obtained raw data from the authors from which we managed to extract effect sizes ourselves; we also included these papers in the analysis.

\section{Scoring Urbanization}

Studies varied widely in methods used to quantify the levels of urbanization of their study sites. To make studies comparable, two observers (EV and GS) independently scored the level of urbanization of each study on a five-level urbanization scale (using a modified version of the scale proposed by Marzluff et al., 2001a):

1. Wildland/natural area: Interior of a large ( $>200 \mathrm{ha}$ ) forest or meadow, with little anthropogenic effects.

2. Rural area: Landscape dominated by anthropogenic effects, such as agriculture (pasture, crop field, orchard, farmland), or very intensive forestry (clear-cuts), with little housing $(<2.5 / \mathrm{ha})$; or a small forest patch $(<200 \mathrm{ha}) /$ forest edge within these types of landscapes.

3. Suburban edge/exurban area: Landscape in the proximity of urban or developed industrial areas, with a low housing density $(<2.5 /$ ha) or a low proportion of built/developed surface ( $<20 \%$, or $>80 \%$ vegetation), e.g., brownfields, golf courses, areas with detached houses; or a small forest patch $(<200 \mathrm{ha}) /$ forest edge within a suburban matrix.

4. Suburban area: Landscape with medium housing density (2.5-10/ha) or medium proportion of built/developed surface (20-50\%; or $50-80 \%$ vegetation), e.g., most urban parks, residential areas with single-family houses, lawns and gardens, university campuses.

5. Urban area: Landscape with high housing density ( $>10 /$ ha, $\left.1,000 / \mathrm{km}^{2}\right)$ or high proportion of built/developed surface ( $>50 \%$; or $<50 \%$ vegetation), e.g., residential areas with multistory buildings and blocks of flat, commercial, service, and industrial buildings.

Information on numbers of sites scored by the two observers, and on between-observer repeatability, is provided in Table S2. Sites that got different scores from the two observers were assigned one of the five scores via subsequent discussion. In most studies $(N=40 ; 78 \%)$, the order of the study sites based on these urbanization scores matched the order indicated by the original authors. However, for some papers $(N=11)$, sites that represented different urbanization levels according to the authors were given equal scores by us.

\section{Data Extraction}

We used correlation coefficients between nest survival (i.e., the probability of nests not failing) and urbanization as our effect size. We calculated these correlation coefficients from the numbers of surviving and failed nests at each study site unless 
already provided in the paper. The numbers of surviving and failed nests were obtained in several ways:

(i) The exact numbers of surviving and failed nests in an experiment were directly reported $(N=22)$ or given to us by the original authors $(N=4)$;

(ii) The numbers could be calculated by multiplying the reported percentage of survived nests sample sizes $(N=20)$;

(iii) If the survival rates were reported in figures as column diagrams $(N=3)$, we measured the height of the columns and calculated the number of surviving and failed nests from these;

(iv) One paper reported daily nest survival rates calculated by Mayfield's method (Mayfield, 1961, 1975) along with the numbers of exposure days; for this paper we calculated the number of failed nests by multiplying daily predation rate by the number of exposure days. Other papers that reported daily nest survival rates $(N=7$, Table S3) were excluded, as we did not find a reliable way to back-calculate the number of survived and failed nests.

There was a single paper that reported only a correlation coefficient (Lumpkin et al., 2012), which we used as our effect size. For all other papers we coded each nest as failed (0) or survived (1), ranked urbanization around the nest according to the five levels on an ordinal scale from the least to the most urbanized based on the urbanization scores assigned by us, and ran a Spearman rank correlation between these two variables for each study. We used the Fisher's $Z$-transformed correlation $(\mathrm{Zr}$ ) value as our effect size (see Section Statistical Analyses below for more explanation for this choice). We excluded studies where only test statistics from regression models other than correlation tests were available for which we did not obtain data from the authors $(N=18$, Table S3). We excluded these studies because the conversion of multivariate regression estimates to correlation coefficients often does not accurately approximate correlation coefficients when calculated from raw data (Aloe, 2015). Sampling error variance of each effect size (Fisher's Zr) was calculated as the reciprocal of the total number of nests minus three.

Some papers ( $N=16$ natural nest studies and $N=20$ artificial nest studies) distinguished between predation and other forms of nest failure (e.g., abandonment, weather destroying the nest, vandalism by humans). Since we were primarily interested in predation, whenever it was possible, we omitted nests that failed due to causes other than predation, and used only nests that survived and nests that failed due to predation. For papers that did not distinguish between sources of nest failure $(N=15$ studies, all on natural nests), we simply used numbers of survived and failed nests to calculate effect sizes, regardless of the actual source of nest failure. Similarly, partially predated nests (i.e., where some eggs or offspring disappeared, but at least one of them survived) were considered as predated in some studies $(N=19)$ and as survived in others $(N=28)$, while some studies were conducted on nests with only one egg $(N=4)$. To test whether these two methodological differences affected our effect sizes, we applied the moderator "source of mortality" as a binary factor to describe whether our effect size was calculated from predation-only mortality or from total mortality, and the moderator "partial predation," also as a binary factor, to code whether failed nests included the partially predated nests or not.

For studies spanning multiple years, we extracted separate effect sizes for each year, with "study year" as a moderator. However, in some papers only pooled data from multiple years were available. In these cases we used the median value of all study years as a measure of "study year." We also recorded the following moderators: whether the study reported observational data collected in a natural population $(N=28)$ vs. experimental data using artificial nests $(N=20)$; the number of eggs per nest (average number for natural nests, exact number for artificial nests); nest position (ground nest or elevated, e.g., on a tree or building); nest height above ground in meters; nest openness (cup nest-a hemispheric, open nest on the ground or a branch; orb nest-a spherical nest closed on top; or cavity nest-one inside a den or a box); the number of days the nest was exposed to predators (the length of the experiment for artificial nest, the length of the nesting cycle for natural nests); and, in case of natural nests, the study species. We also recorded the year and journal in which the paper was published.

\section{Statistical Analyses}

Before conducting analyses, we converted correlation coefficients $r$ (Spearman's $r$ ) into a standard normal metric (using Fisher's $z$-transformation), $Z r$. This was done because $r$ is bounded between -1 and 1 , and thus does not follow a normal distribution (Hedges and Olkin, 1985). All analyses were performed using the transformed values $(\mathrm{Zr})$, but the results were transformed back to correlations $(r)$ for visual presentations. Correlational effect of $r=0.1,0.3$, and 0.5 , can be considered as small, medium and large effect sizes, respectively, following Cohen's (1988) tentative benchmarks. Point estimates from statistical models were considered significantly different from zero when their $95 \%$ Confidence Intervals (CI) did not overlap zero.

We performed all statistical analyses within $\mathrm{R}$ statistical software v3.2.4 (R Core Team, 2016). For meta-analysis and meta-regression we used the metafor package (Viechtbauer, 2010). The phylogenetic tree for the bird species included in the dataset was created based on the global phylogeny of birds (Jetz et al., 2012) and visualized using the ape package (Paradis et al., 2004). We used multilevel meta-analyses, representing a type of linear mixed model (Viechtbauer, 2010; Nakagawa and Santos, 2012), to control for various sources of non-independence in the data. Non-independence can be present when multiple effect sizes are extracted from the same study, multiple effect sizes are available for the same species, and/or due to phylogenetic relationships among species. To take such non-independences into account, we included random intercepts for study identity, species identity (for natural nests), and phylogeny (for natural nests; using phylogenetic meta-analysis, Hadfield and Nakagawa, 2010; Nakagawa and Santos, 2012) in our models.

\section{Meta-Analyses and Meta-Regressions}

We first ran a simple meta-analytical model (an intercept-only model without any moderators) on all available data to examine the overall effect, which tested whether the meta-analytic mean 
was different from zero. This meta-analytic mean represents the overall relationship between urbanization level and nest predation rate over all data. We quantified total heterogeneity in the dataset by computing $I^{2}$ statistic (Higgins et al., 2003; Supplementary Methods S2.1). We also assessed separate metaanalytical models (and quantified heterogeneity) for the two data subsets composed of effect sizes from studies using either artificial or natural nests, respectively. To interpret the difference between the predation rates in differently urbanized habitats, we converted our meta-analytical means from correlation coefficients to odds ratios (OR; Borenstein et al., 2009); both numbers are reported in the Section Results.

We conducted meta-regression analyses to identify variables accounting for heterogeneity across studies. Continuous moderators were standardized prior to the analyses, so that they had a mean of 0 and $S D$ of 1 . Nest height above ground was log-transformed due to skewedness. We first quantified whether the relationship between urbanization and predation differed on average between the two major study approaches, i.e., artificial vs. natural nest studies. To do so, we added nest type (artificial vs. natural) as a moderator. Because the data subsets for artificial and natural nests had different combinations of applicable moderators, we then performed separate metaregression analyses on these two data subsets. We did not construct models with multiple moderators, because the sample sizes of the subsets were inadequate and/or information on key moderators was missing for many data points. For artificial nests we considered the following moderators: nest openness (cup/hole), nest position (elevated/ground/mix), average egg number per nest, study duration, median study year, study publication year, minimum (min) urbanization score of the site gradient $(1 / 2 / 3 / 4)$, maximum (max) urbanization score of the site gradient $(3 / 4 / 5)$. For the natural nests, we considered the following moderators: source of mortality (i.e., whether failures due to other causes than predation were excluded from calculating the effect sizes or not: yes/no), nest openness (cup/hole/orb), nest position (elevated/ground), nest height above ground in meters, average egg number per nest, study duration, median study year, study publication year, minimum urbanization score of the site gradient (1/2/4), maximum urbanization score of the site gradient (3/4/5).

\section{Sensitivity Analyses and Publication Bias}

To test whether our results were sensitive to the way we scored urbanization, we repeated all analyses with effect sizes calculated from alternative urbanization scores based on the authors' scores.

We also assessed evidence for publication bias (Supplementary Methods S2.2), which can affect conclusions of a meta-analytic studies when published studies are biased toward significant findings (Rothstein et al., 2005).

\section{RESULTS}

\section{General Results}

We screened the abstracts of 412 papers, 138 of which were taken forward for full-text screening (Figure S1). We excluded 87 papers based on our inclusion criteria (fully detailed in Table S3).
Our final dataset thus comprised 117 effect sizes from 51 papers published between 1985 and 2015 (Table 1). The median number of nests monitored within a publication was 104 (mean $=177.6$, $S D=246.5$ ); only in eight cases were effect sizes calculated based on sample sizes of more than 500 nests. Almost half of the effect sizes came from studies that scored mortality in natural nests (58, vs. 59 effect sizes for studies using artificial nests). Effect sizes from natural nest observations represented 32 different species from 21 Families within 6 Orders (with 25 species from 16 families belonging to the Order Passeriformes). Most species were represented in our meta-analysis by only one study; only data for the House wren Troglodytes aedon, European magpie Pica pica and Common blackbird Turdus merula were available from 2, 3, and 3 studies, respectively (Table 1). All continents (except for Antarctica) were represented in the meta-analysis, with most data from North America (46 effect sizes from 23 studies) and Europe (46 effect sizes from 15 studies; Table 1 ).

Studies using artificial nests differed from those with natural nests in several aspects of their study design (Table S4). First, artificial (vs. natural) nests were, on average, followed for much shorter periods of time (Mean $\pm S D=12.2 \pm 5.9$ vs. $41.2 \pm$ 21.1 days). Second, studies using artificial nests were more often performed in less urbanized locations. Third, artificial nests were located on the ground in about half of the studies (28 out of 59 effect sizes), whereas natural nests were usually located at least $2 \mathrm{~m}$ above ground level, with only 6 out of 58 effect sizes coming from studies on ground nests. Fourth, artificial nests were usually open, i.e., cup-shaped (90\%; 53 out of 59 effect sizes) and $10 \%$ were hole-like (nesting box/cavity). In contrast, natural nests were open in $62 \%$ of our data points (36 out of 58 effect sizes), and $34.5 \%$ were hole-like. Fifth, failures of artificial nests were always assumed to result from predation (100\%), whereas most studies on natural nests reported overall survival rates that did not distinguish between predation and other sources of mortality (66\%; 38 out of 58 effect sizes). Finally, all artificial nests were considered as predated when at least one egg/offspring died, while in natural nests usually only complete brood loss was counted as a predation event (97\%; 56 out of 58 effect sizes).

\section{Meta-Analyses and Meta-Regressions}

We found no overall relationship between nest survival and level of urbanization: the meta-analytic mean for the slope between urbanization gradient and nest survival was not distinguishable from, and was centered around, zero [meta-analytical mean $(\beta)=-0.003 ; 95 \%$ Confidence Intervals $(\mathrm{CI})=-0.080$ to 0.074 ; $\mathrm{OR}=0.99$; Figure 1, Table S5]. Effect sizes were, at the same time, highly heterogeneous $\left(I^{2}=92.7 \%\right)$. High heterogeneity suggests effects of moderators, and this finding thereby justified our subsequent meta-regression analyses (Higgins and Thompson, 2002).

When meta-analytic means were estimated separately for the studies using artificial vs. natural nests, we found weak evidence for an effect of urbanization on nest survival for both cases. The meta-analytic mean for artificial studies was small and negative, with confidence intervals marginally overlapping with zero, suggesting a decreasing nest survival with increasing urbanization $(\beta=-0.118$; $95 \% \mathrm{CI}=-0.238$ to 0.006 ; $\mathrm{OR}=$ 
TABLE 1 | Summary of the papers included in the meta-analysis.

\begin{tabular}{|c|c|c|c|c|c|}
\hline References & Species latin name & Nest type & $\boldsymbol{k}$ & Data source & Continent \\
\hline Lin et al., 2015 & Accipiter trivirgatus & Natural & 1 & Numbers (reported) & Asia \\
\hline Kuranov, 2008 & Acrocephalus dumetorum & Natural & 1 & Numbers (reported) & Europe \\
\hline Grandmaison and Niemi, 2007 & Agelaius phoeniceus & Natural & 1 & Numbers (reported) & North America \\
\hline Bowman and Woolfenden, 2001 & Aphelocoma coerulescens & Natural & 6 & Percentage (reported) & North America \\
\hline Vennesland and Butler, 2004 & Ardea herodias & Natural & 2 & Percentage (from author) & North America \\
\hline England et al., 1995 & Buteo swainsoni & Natural & 5 & Numbers (reported) & North America \\
\hline Kosiński, 2001 & Carduelis chloris & Natural & 1 & Percentage (reported) & Europe \\
\hline Patten and Bolger, 2003 & $\begin{array}{l}\text { Aimophila ruficeps, Chamaea fasciata, Pipillio } \\
\text { crissalis, Pipillio maculatus }\end{array}$ & Natural & 4 & Numbers (from author) & North America \\
\hline Beck and Heinsohn, 2006 & Corcorax melanorhamphos & Natural & 1 & Numbers (reported) & Australia \\
\hline Brahmia et al., 2013 & Cyanistes caeruleus & Natural & 3 & Numbers (from author) & Africa \\
\hline Vigallon and Marzluff, 2005 & Cyanocitta stelleri & Natural & 1 & Numbers (reported) & North America \\
\hline Reidy et al., 2008 & Dendroica chrysoparia & Natural & 1 & Numbers (reported) & North America \\
\hline Cempulik, 1993 & Gallinula chloropus & Natural & 1 & Numbers (from author) & Europe \\
\hline Newell and Kostalos, 2007 & Hylocichla mustelina & Natural & 1 & Daily predation rates & North America \\
\hline Pretelli et al., 2015 & Hymenops perspicillatus, Pseudoliestes virescens & Natural & 2 & Numbers (reported) & South America \\
\hline Mazumdar and Kumar, 2014 & Nectarinia asiatica & Natural & 1 & Numbers (reported) & Asia \\
\hline Eden, 1985 & Pica pica & Natural & 1 & Numbers (reported) & Europe \\
\hline Antonov and Atanasova, 2003 & Pica pica & Natural & 1 & Numbers (reported) & Europe \\
\hline Sachteleben et al., 1992 & Pica pica & Natural & 1 & Percentage (reported) & Europe \\
\hline Morimoto et al., 2012 & Seiurus aurocapilla & Natural & 1 & Percentage (reported) & North America \\
\hline Misztal et al., 2008 & Sitta europaea & Natural & 1 & Numbers (reported) & Europe \\
\hline Solonen and Ursin, 2008 & Strix aluco & Natural & 10 & Numbers (from author) & Europe \\
\hline Kuranov, 2009 & $\begin{array}{l}\text { Ficedula hypoleuca, Sturnus vulgaris, Parus major, } \\
\text { Phoenicurus phoenicurus }\end{array}$ & Natural & 4 & Percentage (reported) & Asia \\
\hline Newhouse et al., 2008 & Troglodytes aedon & Natural & 1 & Numbers (reported) & North America \\
\hline Hofer et al., 2010 & Troglodytes aedon & Natural & 1 & Numbers (reported) & North America \\
\hline Ibáñez-Álamo and Soler, 2010 & Turdus merula & Natural & 1 & Percentage (reported) & Europe \\
\hline Vogrin, 2000 & Turdus merula & Natural & 1 & Numbers (reported) & Australia \\
\hline Kentish et al., 1995 & Turdus merula & Natural & 1 & Percentage (reported) & Europe \\
\hline Cardilini et al., 2013 & Vanellus miles & Natural & 1 & Numbers (reported) & Australia \\
\hline Kamp et al., 2014 & Vanellus vanellus & Natural & 1 & Numbers (reported) & Europe \\
\hline Thorington and Bowman, 2003 & NA & Artificial & 1 & Percentage (reported) & North America \\
\hline Gering and Blair, 1999 & NA & Artificial & 4 & Figure & North America \\
\hline Wilcove, 1985 & NA & Artificial & 1 & Percentage (reported) & North America \\
\hline van Heezik et al., 2008 & NA & Artificial & 1 & Percentage (reported) & New Zealand \\
\hline López-Flores et al., 2009 & NA & Artificial & 1 & Numbers (reported) & Central America \\
\hline Ryder et al., 2010 & NA & Artificial & 1 & Percentage (reported) & North America \\
\hline Jokimäki and Huhta, 2000 & NA & Artificial & 4 & Percentage (reported) & Europe \\
\hline Melampy et al., 1999 & NA & Artificial & 2 & Percentage (reported) & North America \\
\hline Danielson et al., 1997 & NA & Artificial & 1 & Percentage (reported) & North America \\
\hline Jobin and Picman, 1997 & NA & Artificial & 2 & Percentage (reported) & North America \\
\hline Jobin and Picman, 2002 & NA & Artificial & 2 & Percentage (reported) & North America \\
\hline Jokimäki et al., 2005 & NA & Artificial & 3 & Numbers (reported) & Europe \\
\hline Latta et al., 2012 & NA & Artificial & 1 & Numbers (reported) & North America \\
\hline Sasvári et al., 1995 & NA & Artificial & 18 & Figure & Europe \\
\hline Piper and Catterall, 2004 & NA & Artificial & 6 & Percentage (reported) & Australia \\
\hline Piper et al., 2002 & NA & Artificial & 1 & Percentage (reported) & Australia \\
\hline De Santo and Willson, 2001 & NA & Artificial & 2 & Figure & North America \\
\hline Keyser, 2002 & NA & Artificial & 4 & Numbers (reported) & North America \\
\hline Matthews et al., 1999 & NA & Artificial & 2 & Percentage (reported) & Australia \\
\hline Lumpkin et al., 2012 & NA & Artificial & 1 & Coefficient & North America \\
\hline Czyzowski et al., 2006 & NA & Artificial & 1 & Numbers (reported) & Europe \\
\hline
\end{tabular}

K, Number of effect sizes per study; NA, Not applicable due to artificial nests being used in the study. 


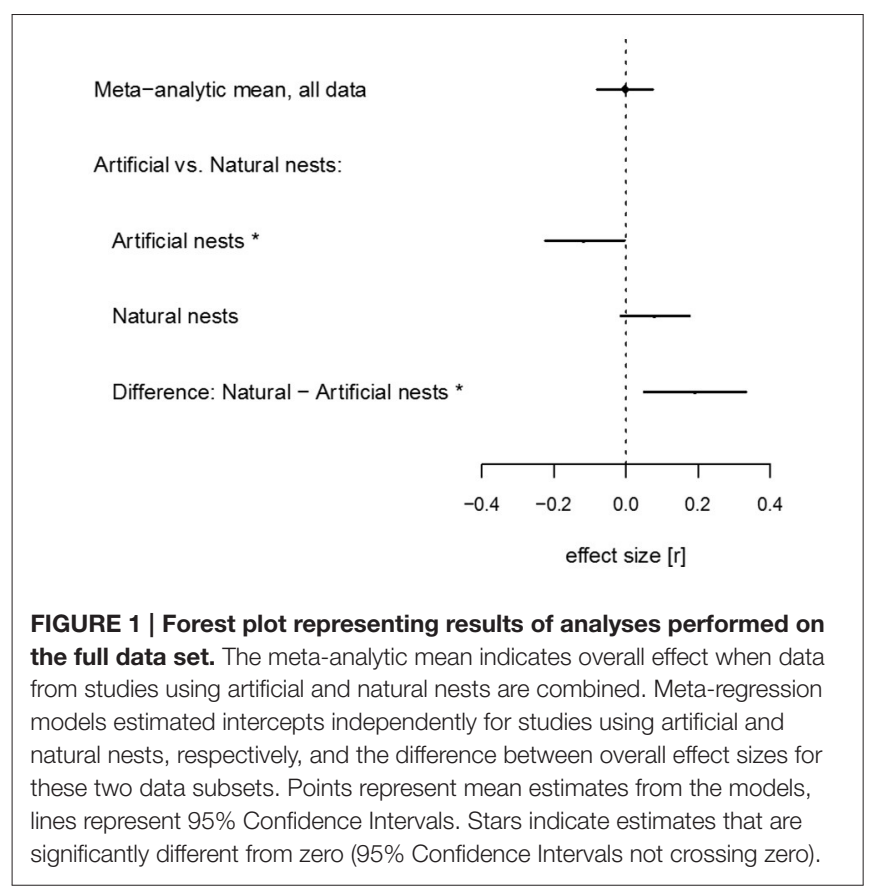

0.65; Figure 1; Table S5). In contrast, the meta-analytic mean for natural nest studies was small and positive; again, confidence intervals were marginally overlapping zero, suggesting that nest survival increased (instead of decreased, see above) with urbanization $(\beta=0.079 ; 95 \% \mathrm{CI}=-0.007$ to 0.165 ; OR $=$ 1.33). The latter effect was lessened when phylogeny was taken into account $(\beta=0.034 ; 95 \% \mathrm{CI}=-0.163$ to 0.228 , Figure 2 , Table S7; we note that phylogenetic effects were not applicable for artificial nest studies, as those did not have associated species). Total heterogeneity was above $90 \%$ in all meta-analytic models (Tables S5-S7).

When we included nest type (artificial vs. natural nests) as a moderator in the meta-regression model on the full data set, the difference between average effect sizes for artificial and natural nests was small but statistically significant (difference between $\beta$ artificial and $\beta$ natural $=0.195 ; 95 \% \mathrm{CI}=0.050$ to 0.332; Figure 1; Table S5), implying that the slopes of the urbanization-mortality relationship differ between the two nest types. Moderators considered affected the relationship between urbanization and nest predation neither in artificial nest (Figure 2A; Table S6) nor in natural nest studies (Figure 2B; Table S7). When we used species identity as a moderator, we found high variation among species (Figure S2, Table S8); note, however, that most species were represented with only one study in the meta-analysis, making further interpretations of this latter result difficult.

\section{Sensitivity Analyses and Publication Bias}

All analyses using alternative urbanization scores (based on the quantification of urbanization levels by the original study authors) had results qualitatively identical to these from the main analyses (Tables S9-S12), indicating that our results are robust to the way urbanization was scored.
We found no evidence for publication bias. Visual inspection of funnel plots and Egger's regression test revealed no indication of funnel shape asymmetry [Figure $3 ; t_{(115)}=0.716, p=0.476$ ]. A trim-and-fill method also implied that there were no missing effect sizes, consistent with the absence of publication bias.

\section{DISCUSSION}

Overall, our meta-analysis did not detect any strong relationship between urbanization and nest mortality. However, predation rates of artificial nests and of natural nests showed opposite trends in their relationships with urbanization: namely, the chance of natural nests to fail tended to decrease (i.e., the odds of survival of natural nests increased by 33\%) with increasing urbanization, whereas the trend in artificial nests was significantly different, and in the opposite direction (i.e., the odds of survival was about $35 \%$ lower in more urbanized habitats). None of our considered moderators, ecological or methodological, explained the variation in effect sizes consistently in either study type, although our sensitivity analyses suggest nest openness may have an effect (Table S11, Supplementary Discussion S3.1).

The weak positive trend for a correlation between nest survival and urbanization in natural nests is in line with the "predatorsafe zone hypothesis" (Gering and Blair, 1999; Ryder et al., 2010), which assigns the lower predation risk in cities as a principal reason of why certain prey species can thrive in urban habitats. Lower predation rates can be the result of low abundance of nest predators (Møller, 2012). However, many potential nest predator species are found in higher abundances in cities than in the surrounding natural habitats (Jokimäki and Huhta, 2000; Haskell et al., 2001). This apparent contradiction is called the "nest predation paradox" (Fischer et al., 2012). This paradox might be resolved in several ways. First, some prey species are often extremely abundant and/or found in higher densities in more urban habitats (McKinney, 2006). Thus, despite the high absolute numbers of nest predators, their relative abundance to prey can still be low compared to natural habitats (Fischer et al., 2012). Second, urbanization changes predator species composition (Rodewald and Kearns, 2011). This shift can mean a decrease in specialized ("strong") nest predators and an increase in opportunistic ("weak") nest predators (Stracey, 2011). For example, snakes, which are often specialized nest predators, are less abundant in cities than in rural areas (Patten and Bolger, 2003). In contrast, house cats, which are both fed by humans and hunt for live prey, and thus are mostly opportunistic nest predators, become more abundant with housing density (Sims et al., 2008), although they might be less common (or less often outdoors) in city centers compared to suburbs. Third, potential predators may specialize on different prey in urban than in rural areas as the most abundant prey species might differ between them, which can relax predation pressure on less abundant species (Fischer et al., 2012). Alternatively, in the case of omnivorous predator species, the shift can be toward anthropogenic food sources that are easier to access, which can relax the actual predation pressure on all prey species (Rodewald 
A

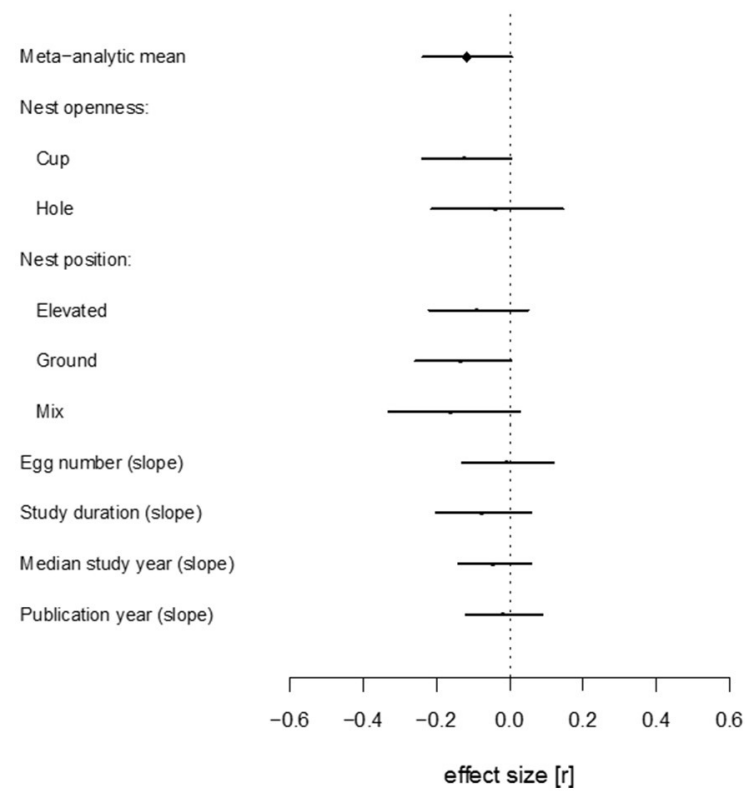

B
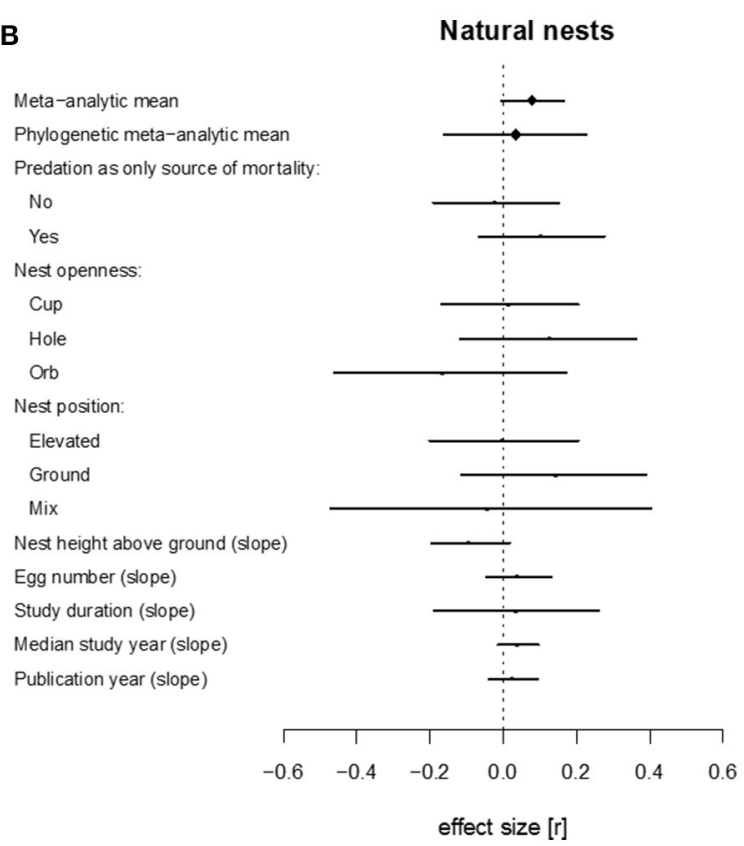

FIGURE 2 | Forest plots of effects size estimates for the studies using artificial nests (A) and natural nests (B). Positive estimate value for meta-analytic mean indicates higher survival in more urbanized habitats. Positive estimate values for moderators can be interpreted as increased likelihood positive effect sizes (higher survival in more urbanized habitats) with increasing values of a continuous moderator, or for a given level of a categorical moderator.
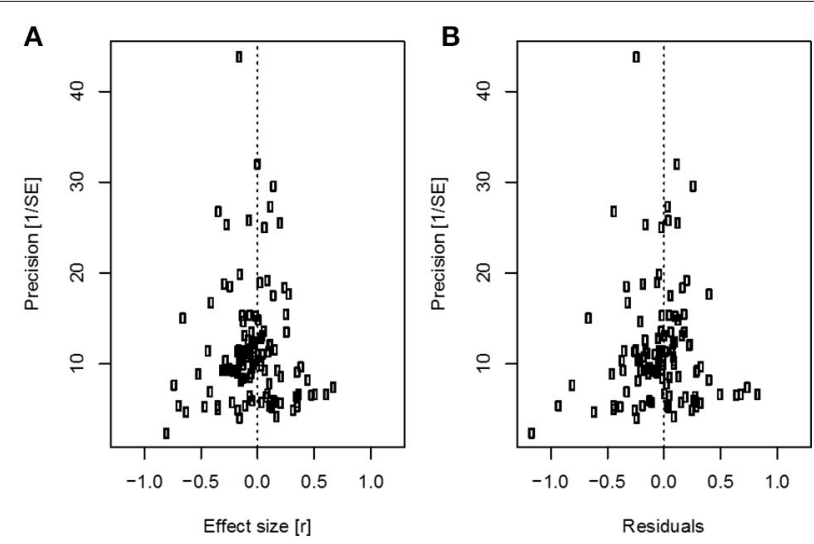

FIGURE 3 | Funnel plots used to estimate publication bias in the data set. (A) Effect size estimates from plotted against their precision; (B) Residual effect sizes from the model with nest type (artificial nest/natural nests) used as a moderator. The dashed line indicates zero, i.e., no relationship between nest mortality and urbanization scores.

et al., 2011). Finally, higher abundance of nest predators in urban habitats can facilitate local adaptation in the behavior of their prey. As high predation pressure in cities should eliminate those individuals that could not effectively defend their nests from predators (either by hiding their nests or actively mobbing predators), the current urban prey population is better at nest defense and thus has higher survival rates than rural prey (Stracey, 2011).
In contrast to natural nests, we found a decreasing trend in the survival of artificial nests with increasing urbanization. This result is in line with a meta-analysis which revealed more predation on artificial nests with increasing fragmentation of forest habitats (Hartley and Hunter, 1998). Also, similar to our findings, a number of studies showed that predation rates in artificial nests often do not reflect those observed in natural nests (Haskell, 1995; Weidinger, 2001; Moore and Robinson, 2004; Robinson et al., 2005), although one study that used artificial and natural nests in the same conditions did not find significant difference between the two (Blair, 2004). The discrepancy between artificial and natural nests may be explained by several different mechanisms. First, our sensitivity analyses on natural nests indicated that predation rates of cavity nests and open nests change differently with urbanization (Table S11). Namely, cavity nests are predated significantly less in urban than in rural habitats, while open nests show no such habitat difference. Since the majority of artificial nest studies were conducted on open nests, their results are more comparable to those from natural open nests than to those from hole-like nests (which are also likely to be located high above the ground and exposed to different conditions). Second, as mentioned above, it is hypothesized that local adaptation may make urban bird parents better at nest defense behavior than their non-urban conspecifics (Stracey, 2011). As artificial nests are not defended by parents, they may be more likely to be depredated in urban habitats than natural nests. Third, the local adaptation hypothesis also suggests that urban birds are better at hiding their nests from predators (Stracey, 2011). As the locations of artificial 
nests are chosen by the experimenters, rather than the birds themselves, nests may be placed in more conspicuous places in urban habitats, thus predators can find them more easily, resulting in a higher predation rate. Fourth, although artificial nests try to emulate natural nests as much as possible, they might still be perceived by predators as novel compared to natural nests. It has been hypothesized that urban animals show less food neophobia (i.e., are more likely to accept novel food sources) than their rural conspecifics (Sol et al., 2011), and thus nonurban predators may be aversive toward artificial nests. Fifth, some discrepancy between the results of natural vs. artificial nest studies may come from the fact that partially predated nests were counted as survived in most natural nest studies, whereas they were counted as predated in artificial nest studies. Partial predation may be more common in cities where the predator is more likely to be interrupted by human disturbance while feeding on a nest. Finally, we cannot exclude the possibility that the real predation pressure on natural nests is higher in cities than in rural habitats, as studies on artificial nests suggest, but the effect is masked by sampling bias. Urban natural nests that were not concealed or defended well-enough may already have been predated before the researchers found them, and thus not included in the sample, while this might not be the case in rural habitats. The resulting sampling bias may lead to a seemingly higher predation rate in rural compared to urban habitats.

In conclusion, our results show that natural nests tend to be less predated in urban habitats than in rural habitats, but this trend is not reflected by studies on artificial nests. We have several recommendations for future studies addressing the relationship of urbanization and nest predation. First, we suggest that the cause of nest failure should be identified as precisely as possible, because both predation and other forms of mortality (weather, nest abandonment, vandalism by humans) can vary with urbanization, affecting the overall nest survival. Second, to identify whether variation is due to differences between species, multiple populations of the same species should be studied, and studies should preferably include data from multiple species. Third, data from the currently available literature is not sufficient for more sophisticated analyses, such as testing multiple biological and ecological factors in the same model and possible interactions between them, therefore more studies, with more balanced design for ecological characteristics such as nest height and nest openness, are required. Finally, as patterns derived from studies using artificial nests often do not qualitatively reflect those derived from natural nests, researchers should perform studies where artificial and natural nests with similar characteristics are monitored within the same area (e.g., Blair, 2004), and investigate sampling bias. Such validation is important to draw firm conclusions regarding

\section{REFERENCES}

Aloe, A. M. (2015). Inaccuracy of regression results in replacing bivariate correlations. Res. Synth. Methods 6, 21-27. doi: 10.1002/jrsm.1126

Antonov, A., and Atanasova, D. (2003). Small-scale differences in the breeding ecology of urban and rural Magpies Pica pica. Ornis Fenn. 80, 21-30. the level of predation in urban vs. rural areas in future studies.

\section{CODE AND DATA AVAILABILITY}

All data used in this manuscript are available in the Supplementary Material of this paper (Supplementary Data). The R scripts for all analyses are available at GitHub (https:// github.com/mlagisz/nest_predation_MA).

\section{AUTHOR CONTRIBUTIONS}

EV, PS, ND, and SN conceived and designed the study, EV and GS collected and proofed data, ML and SN run the analyses and created the figures. The first version of the manuscript was written by EV (Introduction, Methods: Data collection, Discussion) and ML (Methods: Statistical analyses, Results); all authors contributed to revisions.

\section{FUNDING}

EV was supported by Deutsche Bundesstiftung Umwelt's international scholarship grant (30015/588) during data collection and by the UNKP-2016-3-IV "New National Excellence Program" of the Ministry of Human Capacities of Hungary during data analysis and preparation of the manuscript. GS was supported by the Hungarian National Research, Development and Innovation Office (NKFIH K112838 and PD 120998) grants. SN was supported by an ARC Future Fellowship (FT130100268). Publication fees were taken from a grant provided by the Deutsche Forschungsgemeinschaft (SP 1450/3-1) granted to PS.

\section{ACKNOWLEDGMENTS}

We thank the following authors for answering questions about their studies and providing additional information and/or raw data: C. C. Catterall, P. Cempulik, T. Csörgö, J. C. Gering, C. Holzapfel, C. C. Hofer, J. D. Ibáñez-Alamo, L. Jerzak, M. A. Patten, J. L. Reidy, A. D. Rodewald, R. Scheifler, T. Solonen, C. M. Stracey, R. G. Vennesland and D.S. Wilcove. We also thank A. Rutten for her help with programming, and M. Moiron and J. Limonet for helping with the translation of two foreign-language papers.

\section{SUPPLEMENTARY MATERIAL}

The Supplementary Material for this article can be found online at: http://journal.frontiersin.org/article/10.3389/fevo. 2017.00029/full\#supplementary-material

Ausprey, I. J., and Rodewald, A. D. (2011). Postfledging survivorship and habitat selection across a rural-to-urban landscape gradient. Auk 128, 293-302. doi: 10.1525/auk.2011.10158

Baker, P. J., Molony, S. E., Stone, E., Cuthill, I. C., and Harris, S. (2008). Cats about town: is predation by free-ranging pet cats Felis catus likely to affect urban bird populations? Ibis 150, 86-99. doi: 10.1111/j.1474-919X.2008.00836.x 
Balogh, A. L., Ryder, T. B., and Marra, P. P. (2011). Population demography of Gray Catbirds in the suburban matrix: sources, sinks and domestic cats. J. Ornithol. 152, 717-726. doi: 10.1007/s10336-011-0648-7

Beale, C. M., and Monaghan, P. A. T. (2004). Human disturbance: people as predation-free predators? J. Appl. Ecol. 41, 335-343. doi: 10.1111/j.0021-8901.2004.00900.x

Beck, N. R., and Heinsohn, R. (2006). Group composition and reproductive success of cooperatively breeding white-winged choughs (Corcorax melanorhamphos) in urban and non-urban habitat. Austral Ecol. 31, 588-596. doi: 10.1111/j.1442-9993.2006.01589.x

Blair, R. (2004). The effects of urban sprawl on birds at multiple levels of biological organization. Ecol. Soc. 9:2. doi: 10.5751/ES-00688-090502

Borenstein, M., Hedges, L. V., Higgins, J. P. T., and Rothstein, H. R. (2009). Introduction to Meta-Analysis. Chichester: John Wiley \& Sons, Ltd.

Bowman, R., and Woolfenden, G. E. (2001). "Nest success and the timing of nest failure of Florida Scrub-Jays in suburban and wildland habitats," in Avian Ecology and Conservation in an Urbanizing World (Norwell, MA: Kluwer Academic Publishers), 383-402. doi: 10.1007/978-1-4615-1531-9_18

Brack, V. J., Cable, T. T., and Driscoll, D. E. (1985). Food habits of urban American kestrels, Falco sparverius. Proc. Indiana Acad. Sci. 94, 607-614.

Brahmia, Z., Scheifler, R., Crini, N., Maas, S., Giraudoux, P., and Benyacoub, S. (2013). Breeding performance of blue tits (Cyanistes caeruleus ultramarinus) in relation to lead pollution and nest failure rates in rural, intermediate, and urban sites in Algeria. Environ. Pollut. 174, 171-178. doi: 10.1016/j.envpol.2012.11.028

Brown, L. M., and Graham, C. H. (2015). Demography, traits and vulnerability to urbanization: can we make generalizations? J. Appl. Ecol. 52, 1455-1464. doi: 10.1111/1365-2664.12521

Cardilini, A. P. A., Weston, M. A., Nimmo, D. G., Dann, P., and Sherman, C. D. H. (2013). Surviving in sprawling suburbs: suburban environments represent high quality breeding habitat for a widespread shorebird. Landsc. Urban Plan. 115, 72-80. doi: 10.1016/j.landurbplan.2013.04.001

Cempulik, P. (1993). Breeding ecology of the moorhen Gallinula chloropus in Upper Silesia (Poland). Acta Ornithol. 28, 75-89.

Chace, J. F., and Walsh, J. J. (2006). Urban effects on native avifauna: a review. Landsc. Urban Plan. 74, 46-69. doi: 10.1016/j.landurbplan.2004.08.007

Chamberlain, D. E., Cannon, A. R., Toms, M. P., Leech, D. I., Hatchwell, B. J., and Gaston, K. J. (2009). Avian productivity in urban landscapes: a review and meta-analysis. Ibis 151, 1-18. doi: 10.1111/j.1474-919X.2008.00899.x

Chiron, F., and Julliard, R. (2007). Responses of songbirds to magpie reduction in an urban habitat. J. Wildl. Manage. 71, 2624-2631. doi: 10.2193/2006-105

Clarke, J. A. (1983). Moonlight's influence on predator / prey interactions between short-eared owls (Asio flammeus) and deermice (Peromyscus maniculatus). Behav. Ecol. Sociobiol. 13, 205-209. doi: 10.1007/BF00299924

Cohen, J. (1988). Statistical Power Analysis for the Behavioural Sciences, 2nd Edn. Hillsdale, NJ: Erlbaum.

Czyzowski, P., Kapinski, M., and Drozd, L. (2006). A comparison predators pressure on the adroitness of pheasant hatching in urban and agricultural areas. Ann. Univ. Mariae Curie Skłodowska. Sect. EE Zootech. 24, 429-435.

Danielson, W. R., DeGraaf, R. M., and Fuller, T. K. (1997). Rural and suburban forest edges: effect on egg predators and nest predation rates. Landsc. Urban Plan. 38, 25-36. doi: 10.1016/S0169-2046(97)00016-9

De Santo, T. L., and Willson, M. F. (2001). Predator abundance and predation of artificial nests in natural and anthropogenic coniferous forest edges in southeast Alaska. J. Field Ornithol. 72, 136-149. doi: 10.1648/0273-8570-72. 1.136

Eden, S. F. (1985). The comparative breeding biology of mapgies Pica pica in an urban and a rural habitat (Aves: Corvidae). J. Zool. 205, 325-334. doi: 10.1111/j.1469-7998.1985.tb05620.x

England, S. A., Estep, J. A., and Holt, W. R. (1995). Nest-site selection and reproductive performance of urban-nesting Swainson's hawks in the Central Valley of California. J. Raptor Res. 29, 179-186.

Faeth, S. H., Warren, P. S., Shochat, E., and Marussich, W. A. (2005). Trophic dynamics in urban communities. Bioscience 55, 399-407. doi: 10.1641/00063568(2005)055[0399:TDIUC]2.0.CO;2

Fischer, J. D., Cleeton, S. H., and Miller, J. R. (2012). Urbanization and the predation paradox: the role of trophic dynamics in structuring vertebrate communities. Bioscience 62, 809-818. doi: 10.1525/bio.2012.62.9.6
Francis, C. D., Ortega, C. P., and Cruz, A. (2009). Noise pollution changes avian communities and species interactions. Curr. Biol. 19, 1415-1419. doi: 10.1016/j.cub.2009.06.052

Geffroy, B., Samia, D. S. M., Bessa, E., and Blumstein, D. T. (2015). How naturebased tourism might increase prey vulnerability to predators. Trends Ecol. Evol. (Amst). 30, 755-765. doi: 10.1016/j.tree.2015.09.010

Gering, J. C., and Blair, R. B. (1999). Predation on artificial bird nests along an urban gradient: predatory risk or relaxation in urban environments? Ecography 22, 532-541. doi: 10.1111/j.1600-0587.1999.tb00542.x

Gorenzel, W. P., and Salmon, T. P. (1995). Characteristics of American Crow urban roosts in California. J. Wildl. Manage. 59, 638-645. doi: 10.2307/3801939

Grandmaison, D. D., and Niemi, G. J. (2007). Local and landscape influence on Red-winged blackbird (Agelaius phoeniceus) nest success in Great Lakes coastal wetlands. J. Great Lakes Res. 33, 292-304. doi: 10.3394/03801330(2007)33[292:LALIOR]2.0.CO;2

Hadfield, J. D., and Nakagawa, S. (2010). General quantitative genetic methods for comparative biology: phylogenies, taxonomies and multi-trait models for continuous and categorical characters. J. Evol. Biol. 23, 494-508. doi: 10.1111/j.1420-9101.2009.01915.x

Hartley, M. J., and Hunter, M. L. (1998). A meta-analysis of forest cover, edge effects, and artificial nest predation rates. Conserv. Biol. 12, 465-469. doi: 10.1046/j.1523-1739.1998.96373.x

Haskell, D. G. (1995). Forest fragmentation and nest predation: are experiments with Japanese Quail eggs misleading? Auk 112, 767-770.

Haskell, D. G., Knupp, A. M., and Schneider, M. C. (2001). "Nest predator abundance and urbanization," in Avian Ecology and Conservation in an Urbanizing World, ed J. M. Marzluff (New York, NY: Springer Science + Business Media), 243-258.

Hedges, L. V., and Olkin, I. (1985). Statistical Methods for Meta-Analysis. London, UK: Academic Press.

Higgins, J. P. T., and Thompson, S. G. (2002). Quantifying heterogeneity in a meta-analysis. Stat. Med. 21, 1539-1558. doi: 10.1002/sim.1186

Higgins, J. P. T., Thompson, S. G., Deeks, J. J., and Altman, D. G. (2003). Measuring inconsistency in meta-analyses. BMJ Br. Med. J. 327, 557-560. doi: 10.1136/bmj.327.7414.557

Hofer, C., Gallagher, F. J., and Holzapfel, C. (2010). Metal accumulation and performance of nestlings of passerine bird species at an urban brownfield site. Environ. Pollut. 158, 1207-1213. doi: 10.1016/j.envpol.2010.01.018

Ibáñez-Álamo, J. D., and Soler, M. (2010). Investigator activities reduce nest predation in blackbirds Turdus merula. J. Avian Biol. 41, 208-212. doi: 10.1111/j.1600-048X.2009.04805.x

Jerzak, L. (1997). Magpie Pica pica nest sites in urban habitats in Poland. Acta Ornithol. 32, 69-76.

Jetz, W., Thomas, G. H., Joy, J. B., Hartmann, K., and Mooers, A. O. (2012). The global diversity of birds in space and time. Nature 491, 444-448. doi: $10.1038 /$ nature11631

Jobin, B., and Picman, J. (1997). Factors affecting predation on artificial nests in marshes. J. Wildl. Manage. 61, 792-800. doi: 10.2307/3802186

Jobin, B., and Picman, J. (2002). Predation on artificial nests in upland habitats adjacent to freshwater marshes. Am. Midl. Nat. 147, 305-314. doi: 10.1674/ 0003-0031(2002)147[0305:POANIU]2.0.CO;2

Jokimäki, J., and Huhta, E. (2000). Artificial nest predation and abundance of birds along an urban gradient. Condor 102, 838-847. doi: 10.1650/00105422(2000)102 [0838:ANPAAO]2.0.CO;2

Jokimäki, J., Kaisanlahti-Jokimäki, M.-L., Sorace, A., Fernández-Juricic, E., Rodriguez-Prieto, I., and Jimenez, M. D. (2005). Evaluation of the "safe nesting zone" hypothesis across an urban gradient: a multi-scale study. Ecography 28, 59-70. doi: 10.1111/j.0906-7590.2005.04001.x

Kamp, J., Pelster, A., Gaedicke, L., Karthäuser, J., Dieker, P., and Mantel, K. (2014). High nest survival and productivity of Northern Lapwings Vanellus vanellus breeding on urban brownfield sites. J. Ornithol. 156, 179-190. doi: 10.1007/s10336-014-1114-0

Kentish, B. J., Dann, P., and Lowe, K. W. (1995). Breeding biology of the Common Blackbird Turdus merula in Australia. Emu 95, 233-244. doi: 10.1071/MU9950233

Keyser, A. J. (2002). Nest predation in fragmented forests: landscape matrix by distance from edge interactions. Wilson Bull. 114, 186-191. doi: 10.1676/00435643(2002)114[0186:NPIFFL]2.0.CO;2 
Kosiński, Z. (2001). Effects of urbanization on nest site selection and nesting success of Greenfich Carduelis chloris in Krotoszyn, Poland. Ornis Fenn. 78, 175-183.

Kövér, L., Gyüre, P., Balogh, P., Huettmann, F., Lengyel, S., and Juhász, L. (2015). Recent colonization and nest site selection of the Hooded Crow (Corvus corone cornix L.) in an urban environment. Landsc. Urban Plan. 133, 78-86. doi: 10.1016/j.landurbplan.2014.09.008

Kristan, W. B., Boarman, W. I., and Crayon, J. J. (2004). Diet composition of common ravens across the urban-wildland interface of the West Mojave Desert. Wildl. Soc. Bull. 32, 244-253. doi: 10.2193/00917648(2004)32[244:DCOCRA]2.0.CO;2

Kuranov, B. D. (2008). Peculiarities of nesting biology in the blyth reed warbler (Acrocephallus dumetorum, Passeriformes, Sylviidae) in urban habitats. Zool. Zhurnal 87, 466-475.

Kuranov, B. D. (2009). Nest biology of urban populations of cavity-nesting birds. Contemp. Probl. Ecol. 2, 240-247. doi: 10.1134/S1995425509030138

Latta, S. C., Musher, L. J., Latta, K. N., and Katzner, T. E. (2012). Influence of human population size and the built environment on avian assemblages in urban green spaces. Urban Ecosyst. 16, 463-479. doi: $10.1007 / \mathrm{s} 11252-012-0282-\mathrm{z}$

Leonard, M. L., and Horn, A. G. (2008). Does ambient noise affect growth and begging call structure in nestling birds? Behav. Ecol. 19, 502-507. doi: 10.1093/beheco/arm161

Lesiński, G., Gryz, J., and Kowalski, M. (2009). Bat predation by tawny owls Strix aluco in differently human-transformed habitats. Ital. J. Zool. 76, 415-421. doi: $10.1080 / 11250000802589535$

Lin, W. L., Lin, S. M., Lin, J. W., Wang, Y., and Tseng, H. Y. (2015). Breeding performance of Crested Goshawk Accipiter trivirgatus in urban and rural environments of Taiwan. Bird Study 62, 177-184. doi: 10.1080/00063657.2015.1005570

López-Flores, V., MacGregor-Fors, I., and Schondube, J. E. (2009). Artificial nest predation along a Neotropical urban gradient. Landsc. Urban Plan. 92, 90-95. doi: 10.1016/j.landurbplan.2009.03.001

Lumpkin, H. A., Pearson, S. M., and Turner, M. G. (2012). Effects of climate and exurban development on nest predation and predator presence in the southern Appalachian Mountains (U.S.A.). Conserv. Biol. 26, 679-688. doi: $10.1111 /$ j.1523-1739.2012.01851.x

Marzluff, J. M., and Neatherlin, E. (2006). Corvid response to human settlements and campgrounds: causes, consequences, and challenges for conservation. Biol. Conserv. 130, 301-314. doi: 10.1016/j.biocon.2005. 12.026

Marzluff, J. M., Bowman, R., and Donnelly, R. (2001a). "A historical perspective on urban bird research: trends, terms, and approaches," in Avian Ecology and Conservation in an Urbanizing World (Norwell, MA: Kluwer Academic Publishers), 1-17.

Marzluff, J. M., Bowman, R., and Donnelly, R. (2001b). Avian Ecology and Conservation in an Urbanizing World. Norwell, MA: Kluwer Academic Publishers.

Matthews, A., Dickman, C. R., and Major, R. E. (1999). The influence of fragment size and edge on nest predation in urban bushland. Ecography 22, 349-356. doi: 10.1111/j.1600-0587.1999.tb00572.x

Mayfield, H. F. (1961). Nesting success calculated from exposure. Wilson Bull. 73, 255-261.

Mayfield, H. F. (1975). Suggestions for calculating nest success. Wilson Bull. 87, $456-466$

Mazumdar, A., and Kumar, P. (2014). Difference in nesting ecology of purple sunbird Nectarinia asiatica among urban and rural habitats in New Delhi, India. Avocetta 38, 29-35.

McCleery, R. A., Lopez, R. R., Silvy, N. J., and Gallant, D. L. (2008). Fox squirrel survival in urban and rural environments. J. Wildl. Manage. 72, 133-137. doi: $10.2193 / 2007-138$

McKinney, M. L. (2006). Urbanization as a major cause of biotic homogenization. Biol. Conserv. 127, 247-260. doi: 10.1016/j.biocon.2005.09.005

Melampy, M. N., Kershner, E. L., and Jones, M. A. (1999). Nest predation in suburban and rural woodlots of northern Ohio. Am. Midl. Nat. 141, 284-292. doi: 10.1674/0003-0031(1999)141[0284:NPISAR]2.0.CO;2

Misztal, K., Europaea, S., and Gradientu, L. W. U. (2008). Breeding biology of Wrocław population of Nuthatch Sitta europaea L. Przeglad Przyr. 19, 131-164.
Moher, D., Liberati, A., Tetzlaff, J., Altman, D. G., and the PRISMA group (2009). Preferred reporting items for systematic reviews and metaanalyses: the PRISMA statement. Ann. Intern. Med. 151, 264-269. doi: 10.7326/0003-4819-151-4-200908180-00135

Møller, A. P. (2012). Urban areas as refuges from predators and flight distance of prey. Behav. Ecol. 23, 1030-1035. doi: 10.1093/beheco/ars067

Møller, A. P., and Ibáñez-Álamo, J. D. (2012). Escape behaviour of birds provides evidence of predation being involved in urbanization. Anim. Behav. 84, 341-348. doi: 10.1016/j.anbehav.2012.04.030

Moore, R. P., and Robinson, W. D. (2004). Artificial bird nests, external validity, and bias in ecological field studies. Ecology 85, 1562-1567. doi: 10.1890/ 03-0088

Morimoto, D. C., Frankel, M. A., Hersek, M., and Wasserman, F. E. (2012). Forest Fragmentation Effects on Ovenbird Populations in the Urban Region of Eastern Massachusetts, USA, Vol. 7. Urban Habitats. Available at: http://urbanhabitats.org/v07n01/forestfragmentation_full.html

Myers, R. E., and Hyman, J. (2016). Differences in measures of boldness even when underlying behavioral syndromes are present in two populations of the song sparrow (Melospiza melodia). J. Ethol. 34, 197-206. doi: $10.1007 / \mathrm{s} 10164-016-0465-9$

Nakagawa, S., and Poulin, R. (2012). Meta-analytic insights into evolutionary ecology: an introduction and synthesis. Evol. Ecol. 26, 1085-1099. doi: 10.1007/s10682-012-9593-z

Nakagawa, S., and Santos, E. S. A. (2012). Methodological issues and advances in biological meta-analysis. Evol. Ecol. 26, 1253-1274. doi: $10.1007 / \mathrm{s} 10682-012-9555-5$

Navara, K. J., and Nelson, R. J. (2007). The dark side of light at night: physiological, epidemiological, and ecological consequences. J. Pineal Res. 43, 215-224. doi: 10.1111/j.1600-079X.2007.00473.x

Newell, F. L., and Kostalos, M. S. (2007). Wood thrush nests in dense understory may be vulnerable to predators. Wilson J. Ornithol. 119, 693-702. doi: 10.1676/05-036.1

Newhouse, M. J., Marra, P. P., and Johnson, L. S. (2008). Reproductive success of house wrens in suburban and rural landscapes. Wilson J. Ornithol. 120, 99-104. doi: $10.1676 / 06-156.1$

Paradis, E., Claude, J., and Strimmer, K. (2004). APE: analyses of phylogenetics and evolution in $\mathrm{R}$ language. Bioinformatics 20, 289-290. doi: 10.1093/bioinformatics/btg412

Patten, M. A., and Bolger, D. T. (2003). Variation in top-down control of avian reproductive success across a fragmentation gradient. Oikos 101, 479-488. doi: $10.1034 / j .1600-0706.2003 .12515 . x$

Piper, S. D., and Catterall, C. P. (2004). Effects of edge type and nest height on predation of artificial nests within subtropical Australian eucalypt forests. For. Ecol. Manage. 203, 361-372. doi: 10.1016/j.foreco.2004.08.005

Piper, S., Catterall, C. P., and Olsen, M. (2002). Does adjacent land use affect predation of artificial shrub-nests near eucalypt forest edges? Wildl. Res. 29, 127-133. doi: 10.1071/WR01072

Prange, S., and Gehrt, S. D. (2004). Changes in mesopredator-community structure in response to urbanization. Can. J. Zool. 82, 1804-1817. doi: 10.1139/z04-179

Pretelli, M. G., Isacch, J. P., and Cardoni, D. A. (2015). Effects of fragmentation and landscape matrix on the nesting success of grassland birds in the Pampas grasslands of Argentina. Ibis 157, 688-699. doi: 10.1111/ibi.12292

R Core Team (2016). R: A Language and Environment for Statistical Computing. Vienna: R Foundation for Statistical Computing. Available online at: http://www.r-project.org/

Reidy, J. L., Stake, M. M., and Thompson, F. R. I. (2008). Golden-cheeked warbler nest mortality and predators in urban and rural landscapes. Condor 110, 458-466. doi: $10.1525 /$ cond.2008.8473

Robinson, W. D., Styrsky, J. N., and Brawn, J. D. (2005). Are artificial bird nests effective surrogates for estimating predation or real bird nests? A test with tropical birds. Auk 122, 843-852. doi: 10.1642/00048038(2005)122[0843:AABNES]2.0.CO;2

Rodewald, A. D., and Kearns, L. J. (2011). Shifts in dominant nest predators along a rural-to-urban landscape gradient. Condor 113, 899-906. doi: $10.1525 /$ cond.2011.100132

Rodewald, A. D., Kearns, L. J., and Shustack, D. P. (2011). Anthropogenic resource subsidies decouple predator-prey relationships. Ecol. Appl. 21, 936-943. doi: 10.1890/10-0863.1 
Rothstein, H. R., Sutton, A. J., and Borenstein, M. (2005). Publication Bias in MetaAnalysis: Prevention, Assessment and Adjustments. Chichester: John Wiley \& Sons Ltd.

Ryder, T. B., Reitsma, R., Evans, B., and Marra, P. P. (2010). Quantifying avian nest survival along an urbanization gradient using citizen- and scientist-generated data. Ecol. Appl. 20, 419-426. doi: 10.1890/09-0040.1

Sachteleben, J., Blick, T., Geyer, A., Kröber, T., and Pönisch, S. (1992). Bruterfolg, siedlungsdichte und raumnutzung der elster (Pica pica) in unterschiedlichen habitaten. J. Ornithol. 133, 389-402. doi: 10.1007/BF01640467

Samia, D. S. M., Nakagawa, S., Nomura, F., Rangel, T. F., and Blumstein, D. T. (2015). Increased tolerance to humans among disturbed wildlife. Nat. Commun. 6:8877. doi: $10.1038 /$ ncomms 9877

Sasvári, L., Csörgő, T., and Hahn, I. (1995). Bird nest predation and breeding density in primordial and man-made habitats. Folia Zool. 44, 305-314.

Seress, G., and Liker, A. (2015). Habitat urbanization and its effects on birds. Acta Zool. Acad. Sci. Hungaricae 61, 373-408. doi: 10.17109/AZH.61.4.373.2015

Seress, G., Bókony, V., Heszberger, J., and Liker, A. (2011). Response to predation risk in urban and rural house sparrows. Ethology 117, 896-907. doi: 10.1111/j.1439-0310.2011.01944.x

Shipley, A. A., Murphy, M. T., and Elzinga, A. H. (2013). Residential edges as ecological traps. Auk 130, 501-511. doi: 10.1525/auk.2013.12139

Sims, V., Evans, K. L., Newson, S. E., Tratalos, J. A., Gaston, K. J., and Sheffield, S. (2008). Avian assemblage structure and domestic cat densities in urban environments. Divers. Distrib. 14, 387-399. doi: 10.1111/j.1472-4642.2007.00444.x

Slabbekoorn, H., and Halfwerk, W. (2009). Behavioural ecology: noise annoys at community level. Curr. Biol. 19, R693-R695. doi: 10.1016/j.cub.2009. 07.002

Sol, D., Griffin, A. S., Bartomeus, I., and Boyce, H. (2011). Exploring or avoiding novel food resources? the novelty conflict in an invasive bird. PLOS ONE 6:e19535. doi: 10.1371/journal.pone.0019535

Sol, D., Lapiedra, O., and González-Lagos, C. (2013). Behavioural adjustments for a life in the city. Anim. Behav. 85, 1101-1112. doi: 10.1016/j.anbehav.2013.01.023

Solonen, T., and Ursin, K. A. (2008). Breeding of tawny owls Strix aluco in rural and urban habitats in southern Finland. Bird Study 55, 216-221. doi: 10.1080/00063650809461525

Sprau, P., Mouchet, A., and Dingemanse, N. J. (2016). Multidimensional environmental predictors of variation in avian forest and city life histories. Behav. Ecol. 28, 59-68. doi: 10.1093/beheco/arw130
Stracey, C. M. (2011). Resolving the urban nest predator paradox: the role of alternative foods for nest predators. Biol. Conserv. 144, 1545-1552. doi: 10.1016/j.biocon.2011.01.022

Templeton, C. N., Zollinger, S. A., and Brumm, H. (2016). Traffic noise drowns out great tit alarm calls. Curr. Biol. 26, R1173-R1174. doi: 10.1016/j.cub.2016.09.058

Thorington, K. K., and Bowman, R. (2003). Predation rate on artificial nests increases with human housing density in suburban habitats. Ecography 26, 188-196. doi: 10.1034/j.1600-0587.2003.03351.x

van Heezik, Y., Ludwig, K., Whitwell, S., and McLean, I. G. (2008). Nest survival of birds in an urban environment in New Zealand. N.Zeal. J. Ecol. 32, 155-165.

Vennesland, R. G., and Butler, R. W. (2004). Factors influencing Great Blue Heron nesting productivity on the pacific coast of Canada from 1998 to 1999. Waterbirds 27, 289-296. doi: 10.1675/1524-4695(2004)027[0289:FIGBHN]2.0. $\mathrm{CO} ; 2$

Viechtbauer, W. (2010). Conducting meta-analyses in R with the metafor package. J. Stat. Softw. 36, 1-48. doi: 10.18637/jss.v036.i03

Vigallon, S. M., and Marzluff, J. M. (2005). Abundance, nest sites, and nesting success of steller's jays along a gradient of urbanization in Western Washington. Northwest Sci. 79, 22-27.

Vogrin, M. (2000). Nesting height and nesting losses of rural and urban Blackbirds Turdus merula. Ornis Svec. 10, 149-154.

Weidinger, K. (2001). How well do predation rates on artificial nests estimate predation on natural passerine nests? Ibis 143, 632-641. doi: 10.1111/j.1474-919X.2001.tb04891.x

Wilcove, D. S. (1985). Nest predation in forest tracts and the decline of migratory songbirds. Ecology 66, 1211-1214. doi: 10.2307/1939174

Conflict of Interest Statement: The authors declare that the research was conducted in the absence of any commercial or financial relationships that could be construed as a potential conflict of interest.

Copyright (c) 2017 Vincze, Seress, Lagisz, Nakagawa, Dingemanse and Sprau. This is an open-access article distributed under the terms of the Creative Commons Attribution License (CC BY). The use, distribution or reproduction in other forums is permitted, provided the original author(s) or licensor are credited and that the original publication in this journal is cited, in accordance with accepted academic practice. No use, distribution or reproduction is permitted which does not comply with these terms. 